\title{
Uso de Sistema de Visão de Baixo Custo para Monitoramento de Distorções Durante Deposições Multicamadas no Processo de Soldagem GMAW
}

\author{
Fagner Guilherme Ferreira Coelho ${ }^{1}$, Alexandre Queiróz Bracarense ${ }^{1}$, Stewen Tamine ${ }^{2}$, Jacques Boursault ${ }^{2}$ (D) \\ ${ }^{1}$ Universidade Federal de Minas Gerais - UFMG, Departamento de Engenharia Mecânica, Laboratório de Robótica, Simulação e Soldagem, Belo Horizonte, \\ $M G$, Brasil. \\ ${ }^{2}$ University of Rennes 1, Mechanical and Production Department, Rennes, Brittany, France.
}

Como citar: Coelho FGF, Bracarense AQ, Tamine S, Boursault J. Uso de sistema de visão de baixo custo para monitoramento de distorções durante deposições multicamadas no processo de soldagem GMAW. Soldagem \& Inspeção. 2020;25:e2524. https://doi.org/10.1590/0104-9224/SI25.24

\begin{abstract}
Resumo: Corpos quando submetidos a variações de temperaturas tendem a apresentar alterações dimensionais. No caso de componentes soldados que são afetados por elevadas temperaturas, distorções são apresentadas devido a modificações permanentes de forma e dimensões provenientes de deformações plásticas que são consequências dos ciclos térmicos desenvolvidos durante o processo de soldagem. De modo a garantir as especificações do projeto e minimizar os efeitos térmicos, é desenvolvido um procedimento de soldagem que dentre outros, define sequência dos passes a serem depositados, bem como tratamentos necessários após o processo. Elevados custos associados a garantia do resultado necessário que minimizem as distorções, remetem a um estudo sobre o controle das deformações a qual os componentes soldados estão submetidos. Com isso, faz-se necessário o desenvolvimento de uma metodologia para monitoramento contínuo e dinâmico das distorções provocadas pelos processos de soldagem a arco elétrico, como o GMAW robotizado. Adotando um sistema de visão de baixo custo, que coleta os pontos em que lasers presos nas partes, tem os feixes projetados em um anteparo durante o processo de soldagem a arco GMAW robotizado, permitindo assim utilizar os dados para realimentar o sistema e garantir novas trajetórias e correções de parâmetros para minimizar as deformações em processos multicamadas.
\end{abstract}

Palavras-chave: Monitoramento; Simulação; Visão computacional; Robótica; Manufatura aditiva.

\section{Use of Low Cost Vision System for Monitoring Distortions During Multilayer Deposition in GMAW Welding Process}

\begin{abstract}
Bodies when subjected to temperature variations tend to show dimensional changes. Welded components, that are affected by high temperatures, present distortions due to permanent changes in shape and dimensions resulting from plastic deformations. These deformations are consequences of the thermal cycles caused by the welding process. In order to guarantee the project specifications and minimize thermal effects, a welding procedure is developed which, among others, defines the sequence of passes to be deposited, as well as necessary treatments after the process. The high costs associated with guaranteeing the necessary result that minimize distortions, refer to a study on the control of deformations to which the welded components are subjected. Thus, it is necessary to develop a methodology for continuous and dynamic monitoring of distortions caused by arc welding processes, such as robotic GMAW. Adopting a low-cost vision system, which collects the points where lasers are fixed on the parts, the beams are projected on a panel during the robotized GMAW arc welding process, thus allowing the data to be used to feed the system and guarantee new trajectories and parameter corrections to minimize deformations in multilayer processes.
\end{abstract}

Key-words: Monitoring; Simulation; Computer vision; Robotics; Additive manufacturing.

\section{Introdução}

A necessidade por uma maior produtividade e qualidade nos processos de soldagem vem evoluindo durante os anos de modo a garantir o resultado do produto final. Esse processo de transferência de calor da fonte para a junta produz uma distribuição não uniforme de temperatura na solda e nas regiões adjacentes que, além de favorecer o processo de fusão localizado do material, pode também ocasionar efeitos indesejáveis, como por exemplo, o surgimento de tensões residuais [1]. 
As tensões residuais de níveis macroscópico e microscópico [2] que surgem na peça devido ao ciclo térmico provenientes da soldagem, causam deformações plásticas não-uniformes, e podem ser classificadas segundo sua direção como: distorções longitudinais, transversais, rotacionais, e distorções angulares, conforme a Figura 1 [3-5].

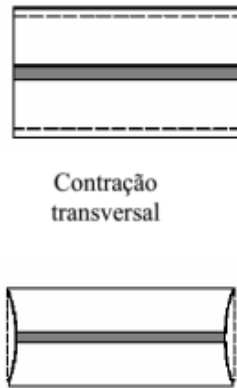

Contração Longitudinal

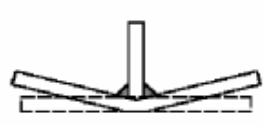

Distorção

Angular

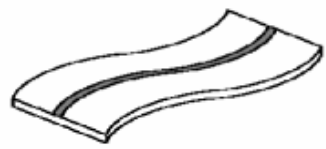

Distorção de flambagem

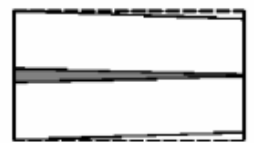

Distorção

Rotacional

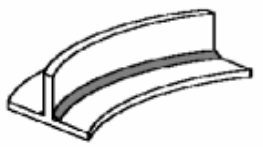

Distorção de flexão

Figura 1. Tipos de distorções $[3,4]$.

As distorções são alterações dimensionais permanentes que ocorrem na estrutura e representam quantitativamente o afastamento da superfície real em relação à superfície idealizada durante a etapa de concepção da estrutura [3], e dependem das propriedades térmicas e mecânicas do material, em particular do coeficiente de expansão, condutividade térmica, limite de escoamento e módulo de elasticidade [1].

A literatura apresenta diversas formas que foram desenvolvidas para o monitoramento das distorções durante a soldagem. Um modo mais simples, porém, sem controle, é através de medições antes e após a soldagem. Desta forma, não é possível acompanhar a evolução das distorções durante o processo, limitando assim as ações preventivas, consequentemente, ocasionando maior número de ações corretivas pós-soldagem, o que encarece a produção.

O sistema proposto por Pereira e Bracarense [6] realiza o monitoramento das distorções de soldagem utilizando sensores a laser apoiados sobre a superfície da peça, que consiste no monitoramento indireto do ângulo de distorção da peça através da movimentação de pontos de feixes luminosos de lasers projetados num anteparo translúcido. Com a progressão das distorções durante a soldagem, os pontos projetados movimentam-se pelo anteparo proporcionalmente as deformações ocorridas na peça, sendo filmados pelo lado oposto ao anteparo translúcido. A discretização dessa filmagem geraram frames com imagens do plano do anteparo contendo o posicionamento dos pontos em função do tempo. Utilizando a regressão linear desses pontos foi possível calcular o ângulo de inclinação que representa a distorção angular ocorrida na peça durante a soldagem e elaborar gráficos que representam o comportamento das distorções em qualquer instante do processo. 0 sistema de monitoramento contínuo de distorções de soldagem com sensores lasers, apresentado na Figura 2 é composto por: (a) mesa de trabalho rígida com niveladores; (b) anteparo translúcido com niveladores; (c) robô; (d) sistema de alimentação elétrica para lasers; (e) sensores laser com suporte para fixação; (f) proteções térmicas para os lasers e sistema de alimentação elétrica; (g) equipamento de filmagem digital 13 megapixels; e (h) proteções negras para auxiliar a filmagem.
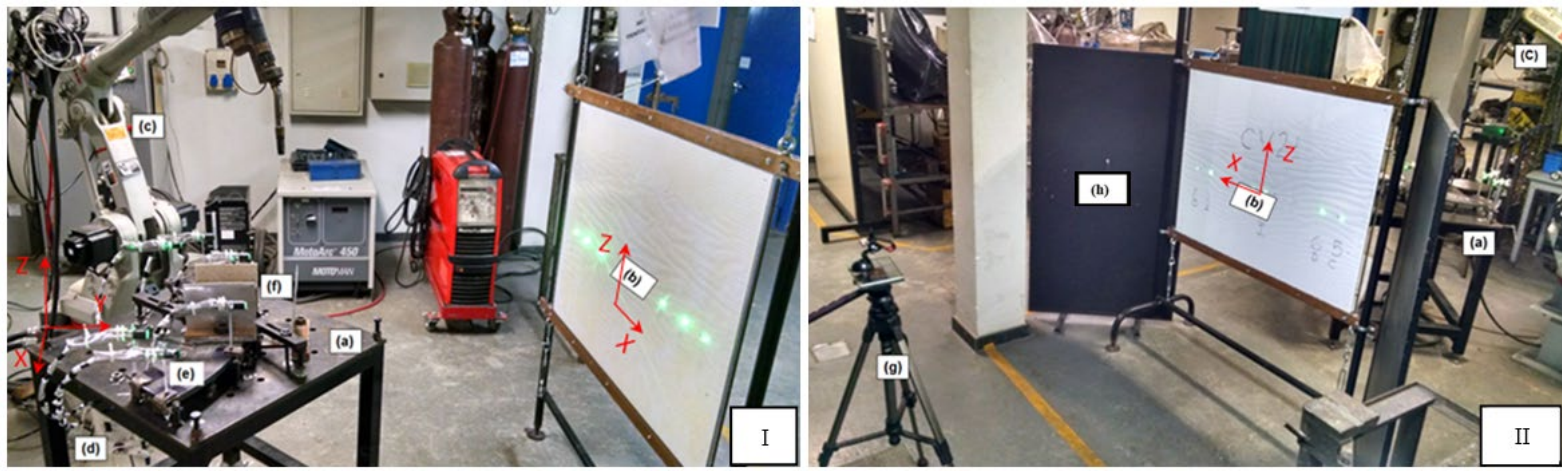

Figura 2. Sistema de monitoramento contínuo no plano X-Z das distorções de soldagem utilizando sensores a laser [4]. (I) Lado da projeção; (II) Lado da Monitoração. 
O uso de técnicas de medição sem contato, que vem se tornando cada vez mais atrativas, permitem o monitoramento durante todo o processo, através de uso de sensores de imagem, que é uma importante ferramenta para a análise. De acordo com a necessidade de monitoramento, o uso de sensores específicos, como câmeras de alta velocidade, torna-se necessários, porém em situações em que uma baixa taxa de aquisição de imagens é possível para avaliar os fenômenos, o uso de câmeras convencionais ou até mesmo uma WebCam, reduz consideravelmente o custo do equipamento.

O emprego de câmeras convencionais apresenta uma alternativa interessante, em situações que sua limitação não seja o problema, e em análise de eventos que ocorrem durante o processo de soldagem. Fenômenos estes que não ocorrem com elevada velocidade, sendo o caso das distorções.

O monitoramento direto e indireto da evolução das distorções durante a soldagem de pequenas chapas de aços engastadas, foi desenvolvido por [7,8], utilizando uma fonte de laser fixa na extremidade livre da chapa e projetando o feixe luminoso em um anteparo milimetrado.

\section{Materiais e Métodos}

O presente trabalho tem como objetivo apresentar uma metodologia que possibilite utilizar um sistema de visão computacional de baixo custo para monitorar o grau de distorção de uma chapa durante o processo de soldagem. Utilizando luz provenientes de lasers que estão instalados na extremidade livre de uma chapa de aço carbono, ao longo da linha da solda [7]. A evolução da distorção é acompanhada considerando o deslocamento do ponto luminoso projetado sobre um anteparo. Os dados coletados do posicionamento do ponto ao longo do tempo são processados e interpretados gerando um gráfico que permite quantificar a deformação em função do tempo, e auxiliar na tomada de decisão para as correções. Os componentes que compõe o sistema para aquisição das informações estão representados na Figura 3, sendo que a WebCam é da marca Logitech modelo C920, o laser é protegido do calor através de uma manta térmica e um tubo de PVC, e o painel para projeção [6] do laser composto de 2 placas de vidro e uma folha de papel milimetrado.

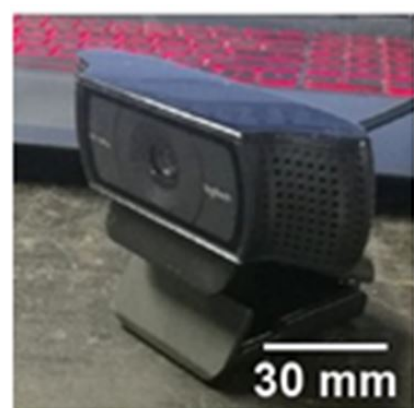

(a)

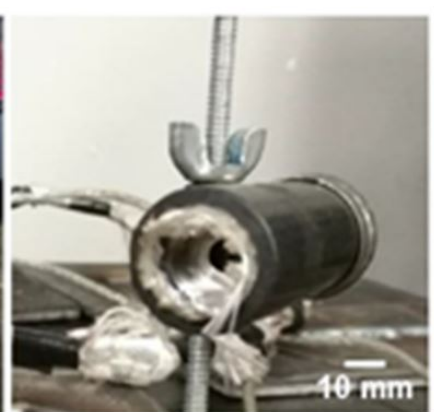

(b)

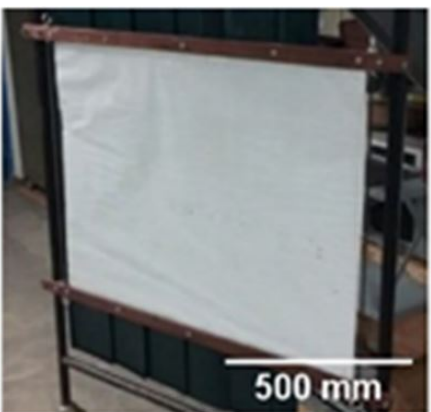

(c)

Figura 3. Componentes do sistema de monitoramento (a) WebCam; (b) Laser; (c) Painel.

O monitoramento será através de sistema de visão e uso de sensores lasers de cor verde, com comprimento de onda de $532 \mathrm{~nm}$ e potência de $1800 \mathrm{~mW}$, sendo estes últimos, montados diretamente na peça a ser soldada, que avaliará a sua deformação por flexão durante as sucessivas deposições de materiais, conforme representado na Figura 2 e proposto por Pereira e Bracarense [6], em que a câmera que fará a captura dos deslocamentos do feixe está posicionada no lado oposto do feixe de luz e do anteparo. O projeto apresentou melhor resultado posicionando a câmera do mesmo lado do feixe laser, reduzindo a perda da incidência do feixe de luz sobre o vidro do anteparo com uma melhor acurácia da captura das imagens pela câmera, devido a menor reflexão da luz, isso também permitiu minimizar o espaço ocupado por todo o sistema, conforme representado na Figura 4.

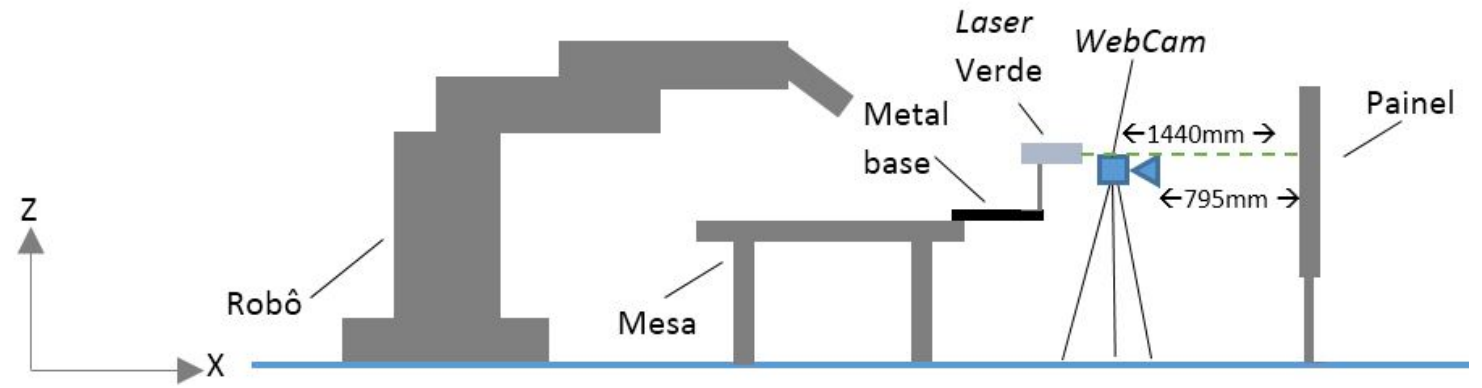

Figura 4. Esquemático do sistema de deslocamento proposto com monitoramento no plano X-Z. 
O processo de calibração da câmera depende diretamente do ambiente a qual estará inserida, com isso, após a definição das distâncias e posicionamentos, o procedimento foi realizado para que as conversões das unidades ocorressem de forma precisa, com isso, o uso do algoritmo de calibração de câmeras [9] se fez necessário para obter as características intrínsecas e extrínsecas do sensor de imagem. Estes parâmetros estão relacionados conforme a Figura 5.

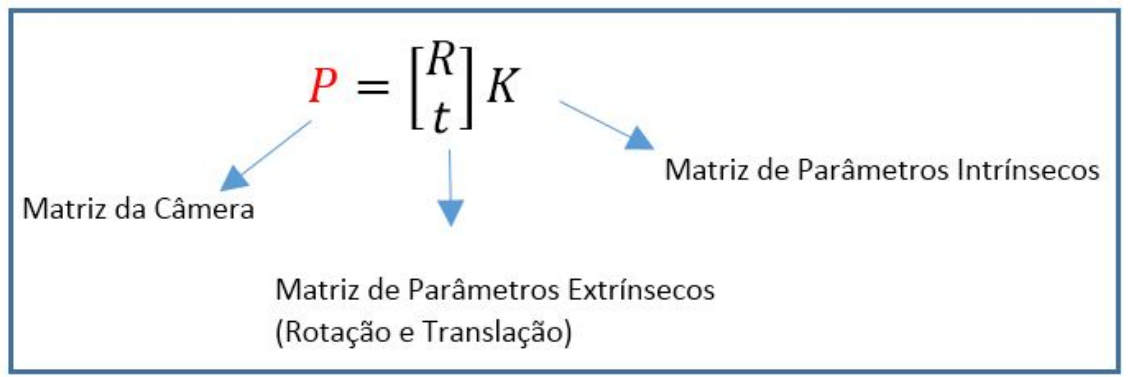

Figura 5. Relação entre os parâmetros de calibração da câmera representados pelas matrizes $P, R, t$ e K.

A matriz $k$ é definida como representado da Equação 1, onde os parâmetros intrínsecos que se referem às características construtivas da câmera, os quais são: distância focal; coeficiente de inclinação, centro óptico são apresentados.

$k=\left[\begin{array}{ccc}f_{x} & 0 & 0 \\ s & f_{y} & 0 \\ c_{x} & c_{y} & 1\end{array}\right]$

sendo: $\left[\begin{array}{cc}c_{x} & c_{y}\end{array}\right]$ - centro óptico (pixels); $\left(f_{x} f_{y}\right)$ - distância focal (pixels); $\left(p_{x} p_{y}\right)$ - tamanho do pixel; $F$ - Distância focal (mm), representada pela distância física da câmera ao plano de projeção; $f_{x}=F / p_{x} ; f_{y}=F / p_{y} ; s-$ coeficiente de inclinação $\left(s=f_{x} \operatorname{tang} \alpha\right) ; \alpha$ está representado na Figura 6 .

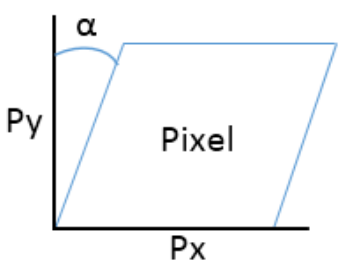

Figura 6. Representação da inclinação do pixel.

A calibração é um procedimento que objetiva, a obtenção de características individuais do instrumento, sendo estas a qualidade, as dimensões construtivas, dentre outras. O resultado de uma calibração visa melhorar a operação de medição, que deve ocorrer com estabilidade estatística, sendo que na prática esta deve ocorrer em condições mais próximas possíveis das condições do instrumento de medida. A teoria e prática do procedimento de calibração é bem abordado por Wei e De Ma [10].

Os parâmetros extrínsecos são provenientes do ambiente, que dependem das melhores configurações possíveis para que a câmera possa obter resultados aceitáveis, dependentes do local de instalação. Estes ajustes estão relacionados com a exposição (quantidade de luz por unidade de área), brilho (percepção provocada pela luminância de um alvo visual), saturação (ajuste da intensidade das cores) e ganho (também chamado de amplificação, é o brilho relativo de uma tela de projeção traseira em comparação com um difusor perfeito). Estes parâmetros que são obtidos através da calibração são utilizados para implementar e otimizar o algoritmo a ser utilizado neste projeto.

Depois de determinar os melhores parâmetros da câmera, define-se a posição do dispositivo composto pela câmera e o laser com feixe de luz verde. O uso da fonte de luz na cor verde, vem da sua maior disponibilidade no laboratório, de modo a minimizar os custos para a realização deste. A distância de $750 \mathrm{~mm}$ do painel em relação à WebCam é a mínima que permite que a câmera visualize todo o painel e com esta distância obteve-se os melhores resultados. De modo a garantir as distâncias fixas, tanto o centro da câmera, sua altura e a distância em relação ao painel, foi desenvolvida uma estrutura com tal finalidade, conforme Figura 7. Nesta configuração, a câmera está a uma distância de 1440mm do painel e a uma altura de $965 \mathrm{~mm}$, mantendo-se alinhado o centro focal do sensor de imagem com o anteparo. 


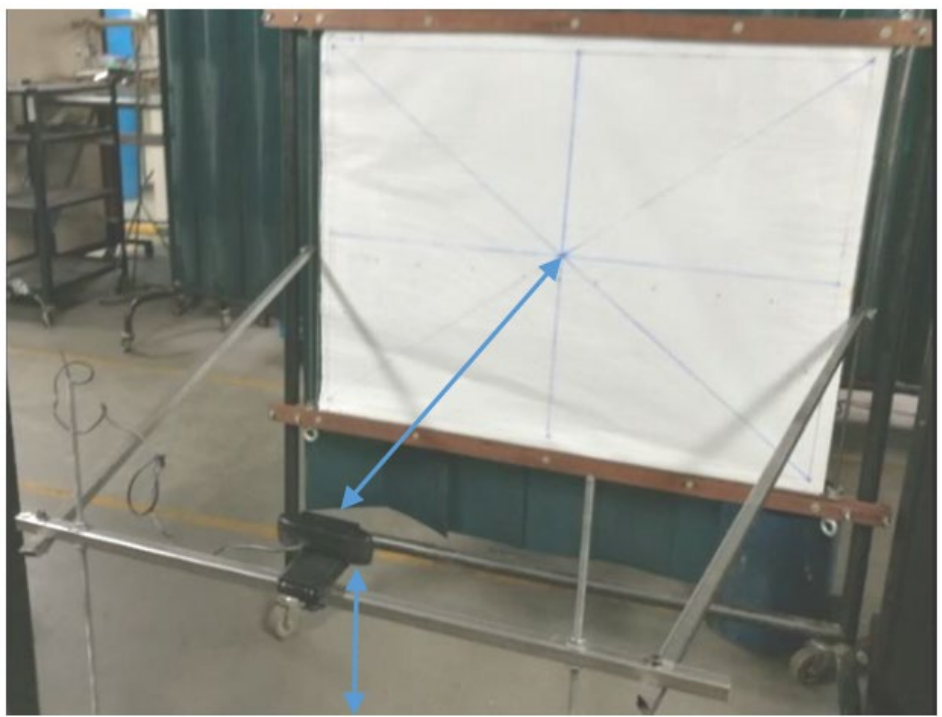

Figura 7. Estrutura fixação da câmera.

Para a avaliação da distorção da chapa durante a soldagem foi considerado a fixação do laser na extremidade livre da peça ao longo da linha da solda, o que minimiza interferências de informações, de modo a otimizar a precisão da medição proposta.

Após posicionar todos os dispositivos, torna-se necessário determinar o fator de conversão para alterar os pixels que a câmera e o programa fornecem em milímetros. Para fazer isso, foram representados em uma folha de papel no painel alguns comprimentos conhecidos, conforme representado na Figura 8. Em seguida, mediu-se todas as distâncias através do algoritmo desenvolvido no Matlab ${ }^{\circledR}$. Estas medidas foram convertidas e armazenadas em um arquivo do Excel e com a média dos seus valores obteve-se o fator de conversão.

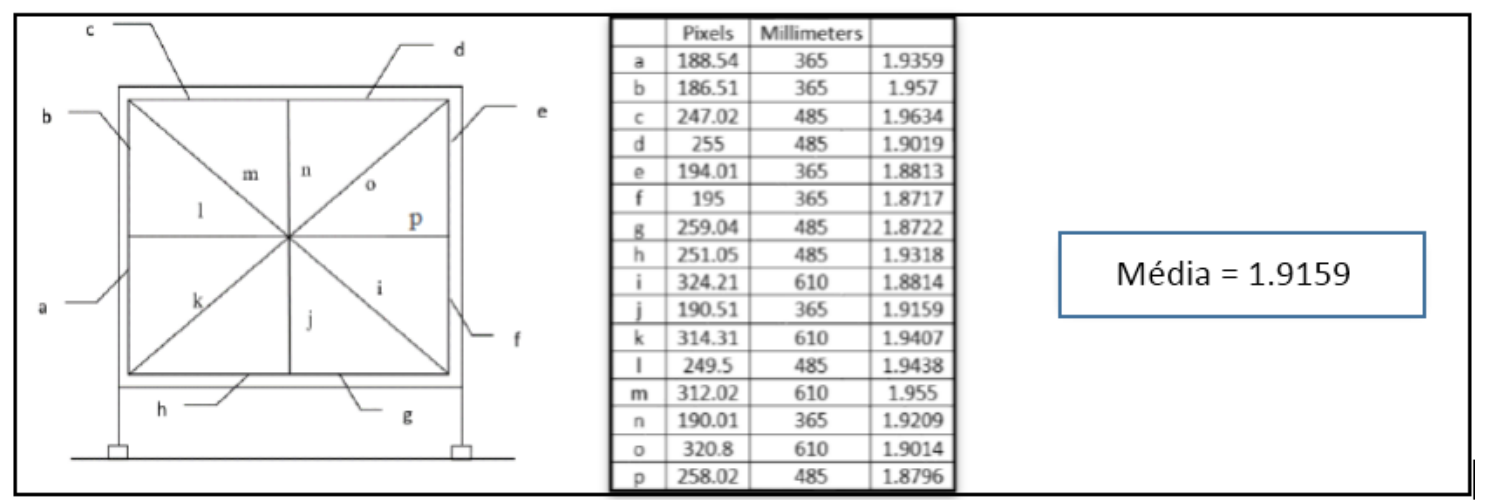

Figura 8. Segmentos com comprimentos conhecidos, e fator de conversão.

Com a etapa de calibração, ajustes do sistema e definição dos fatores de conversão, os resultados foram inseridos no algoritmo para definir a posição de um retângulo em torno do ponto verde proveniente do laser, conforme apresentado na Figura 9. Obteve-se assim o centro do retângulo que fornece a posição em pixels que serão convertidos em milímetros. Ao detectar o ponto sobre o painel, são apresentadas suas coordenadas $(X, Y)$ em pixel e em milímetro respectivamente. Em seguida, o programa gerou todas as coordenadas em um arquivo do MicroSoft ${ }^{\circledR}$ Office Excel e, ao final, plotou um gráfico que permite visualizar a distorção da peça durante o processo de soldagem.

As informações obtidas permitem uma análise quanto a correções na trajetória do manipulador robótico de modo a minimizar as imperfeições constatadas durante o processo de soldagem. Para este sistema uma câmera Webcam, demonstra ser adequada para esta finalidade. Esta câmera está posicionada a uma distância fixa do painel que possui um papel milimetrado, onde o feixe luminoso será projetado. 


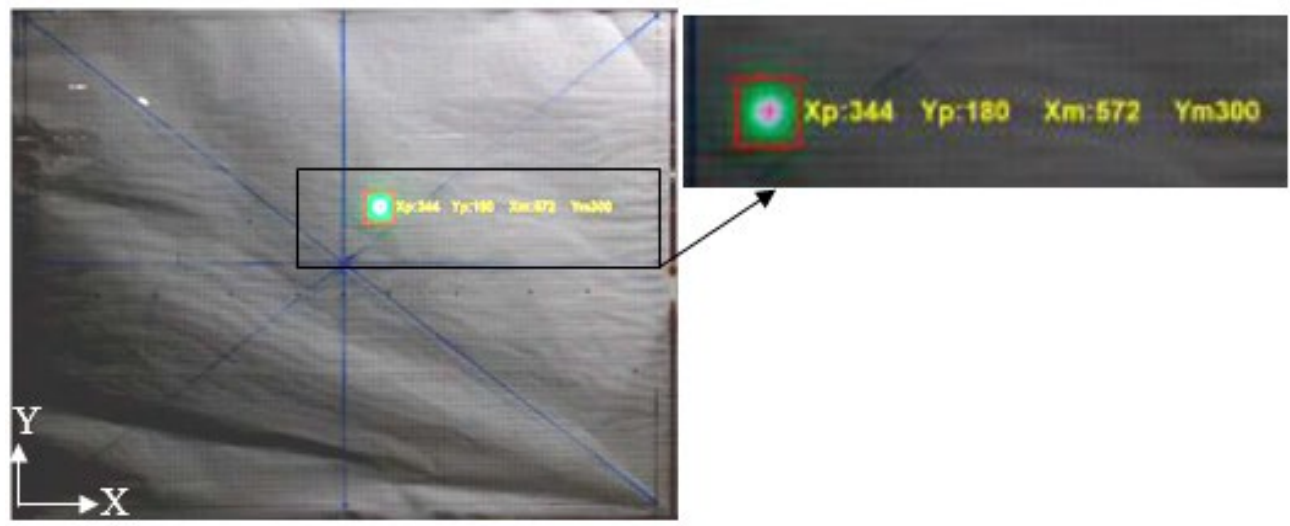

Figura 9. Obtenção das coordenadas do ponto laser projetado no plano X-Y.

Para a soldagem foram utilizadas chapas de Aço carbono SAE1020, com dimensão de $200 \times 100$ e espessura de 6,35mm, em uma extremidade fixada à mesa e a outra livre onde foram montados os sensores lasers, conforme representado na Figura 10. O depósito sucessivo de 5 cordões com comprimento de $100 \mathrm{~mm}$ adotando os parâmetros de soldagem conforme Tabela 1, e com auxílio de um manipulador robótico da YASKAWA Motoman SK-6 foi possível manter constante todos os movimentos, inclinação da tocha, e distâncias do bico de contato peça nas deposições dos cordões.

Tabela 1. Parâmetros de Soldagem.

\begin{tabular}{cc}
\hline Gás & Argônio $+\mathbf{2 0} \% \mathrm{CO}_{2}$ \\
Vazão do gás & $18 \mathrm{l} / \mathrm{min}$ \\
Velocidade de Soldagem & $2,60 \mathrm{~mm} / \mathrm{s}$ \\
Eletrodo & ER-70S6 \\
Diâmetro eletrodo & $0,8 \mathrm{~mm}$ \\
DBCP & $12 \mathrm{~mm}$ \\
\hline
\end{tabular}

Nota: DBCP representa a Distância do Bico de Contato da tocha até a Peça.

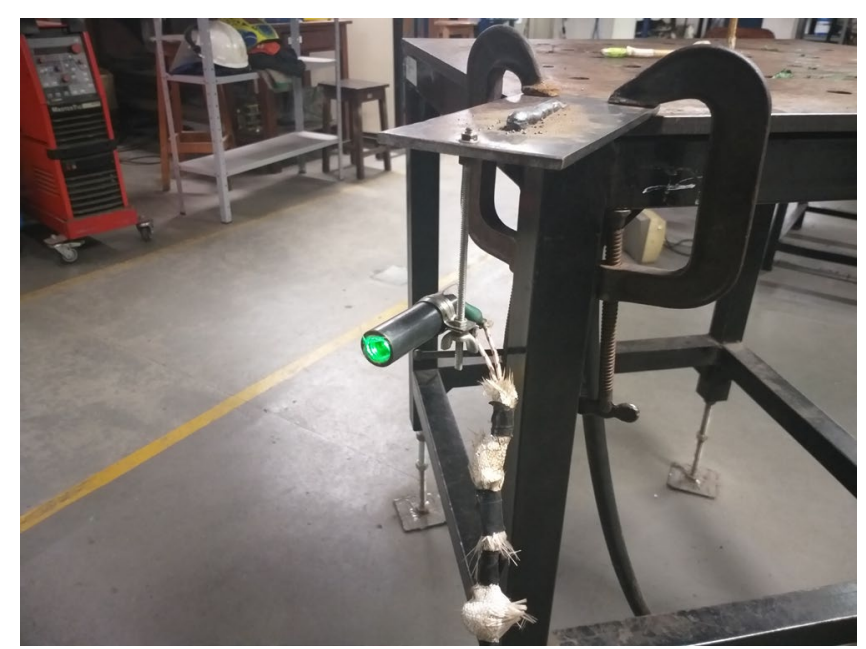

Figura 10. Fixação da chapa e laser.

\section{Resultados e Discussão}

A Tabela 2 apresenta a configuração dos parâmetros para aquisição e a implicação sobre o ambiente, que permite uma melhoria do algoritmo e deteç̧ão do ponto do feixe laser sem que sofra interferência com a iluminação externa. 
Tabela 2. Parâmetros de aquisição.

\begin{tabular}{cc}
\hline Exposição & -7 \\
Brilho & 53 \\
Saturação & 203 \\
Ganho & 0 \\
Compensação de luz de fundo & $\operatorname{sim}$ \\
\hline
\end{tabular}

O Matlab ${ }^{\circledR}$ utiliza linguagem de programação específica baseada em " $C$ ", o que representa uma facilidade em compreender e desenvolver os algoritmos. Baseado na metodologia de rastreamento de objetos, em que o alvo agora é só um elemento verde, para isso, deve-se adotar a obtenção de imagens coloridas de acordo com o padrão RGB, o que permite visualizar e identificar o ponto verde no espaço, conforme descrito no algoritmo representado na Figura 11.

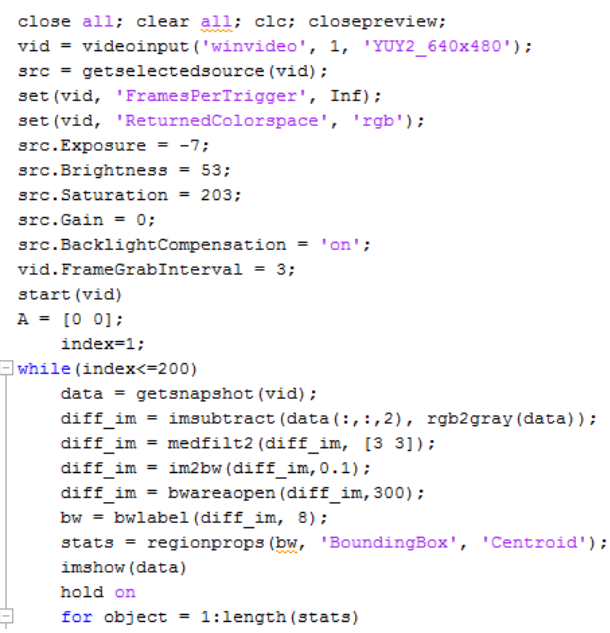

Figura 11. Parte do algoritmo em linguagem " $\mathrm{C}$ " desenvolvido.

Os parâmetros de aquisição também são carregados no algoritmo, bem como os intervalos de aquisição dos quadros, ou seja, a taxa de aquisição de imagens, cujo valor definido foi o suficiente para a validação do programa. O uso de uma variável que permite um incremento do loop para obter 200 fotos, de acordo com o tempo de soldagem, para a geração dos dados serão gravados em um arquivo Excel. Estas imagens são obtidas conforme a configuração anteriormente informada, e então é filtrada a cor verde que é convertida em escala de cinza e posteriormente binarizada. Onde a cor verde é encontrada, cria-se uma caixa retangular ao redor, conforme já representado na Figura 9, e então se determina o seu centro. Com isso, as variações de posição são consideradas devido ao centro geométrico do objeto, e em tempo real é atualizada sua posição.

Com a conversão das coordenadas de pixels para milímetros pelo fator encontrado estas são atualizadas também em tempo real e ao concluir o loop para as 200 imagens obtidas, estas são armazenadas em um arquivo em forma de planilha.

Testes foram realizados utilizando anteparos na tocha, de modo a eliminar possíveis interferências provenientes da luminosidade do arco elétrico, bem como minimizar ações de fontes de luzes externas. A Figura 12 apresenta imagens dos testes e a incidência do feixe laser no anteparo considerando a supressão das fontes de luzes, porém não apresentaram diferenças consideráveis para o comportamento do algoritmo.

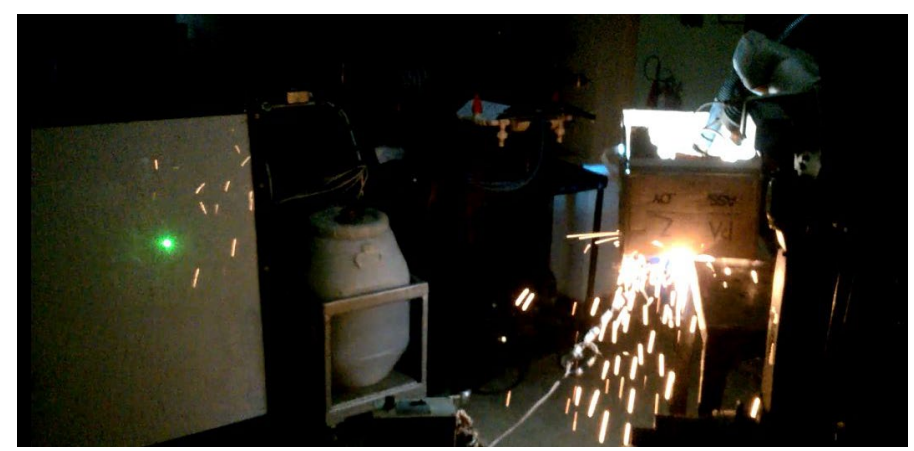

Figura 12. Redução da luminosidade do arco elétrico. 
Nos testes iniciais realizados com a primeira configuração do sistema, ou seja, em que a câmera estava a $1220 \mathrm{~mm}$ do painel, e o laser não estava posicionado ao longo da linha da solda, foi realizado apenas um cordão, e os resultados obtidos estão representados na Figura 13. É possível identificar a deformação no eixo Y, exatamente como era esperado, pois durante uma distorção é possível visualizar no gráfico que ocorre inicialmente uma expansão e posteriormente uma contração. Em Rogana e Bracarense [7] foi comentado que caso não ocorra este movimento de expansão, a restrição imposta pelo próprio comprimento da chapa é muito grande. O gráfico apresenta ainda um movimento de aproximadamente uns $15 \mathrm{~mm}$ em relação as posições inicial e final.

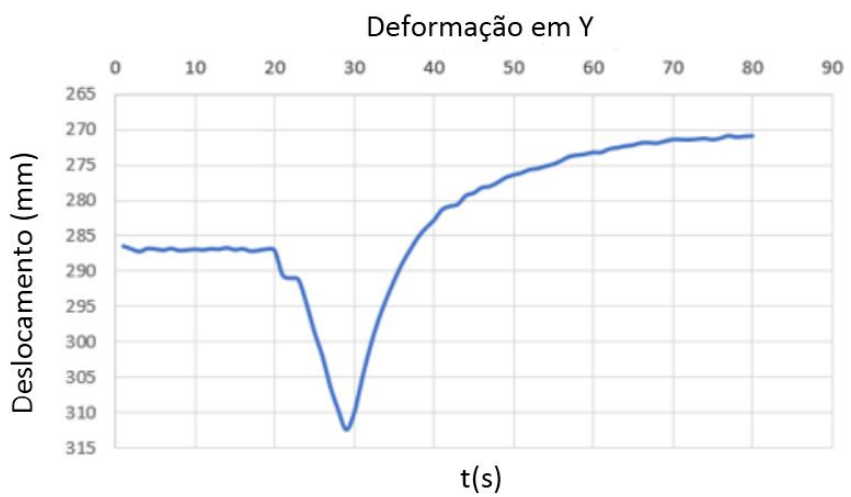

Figura 13. Resultados do primeiro teste.

Com a modificação de posicionamento, ou seja, a câmera disposta do mesmo lado do feixe e a uma distância de $795 \mathrm{~mm}$ até o anteparo, resultou em uma melhora da precisão na conversão de pixels para milímetros, adotou-se fatores distintos para cada eixo, sendo 1.2408 (pixel/mm) para o eixo X e 1.2288 (pixel/mm) para o eixo Y. Com este ajuste, ocorreu um menor movimento ao longo do eixo longitudinal, conforme Figura 14.

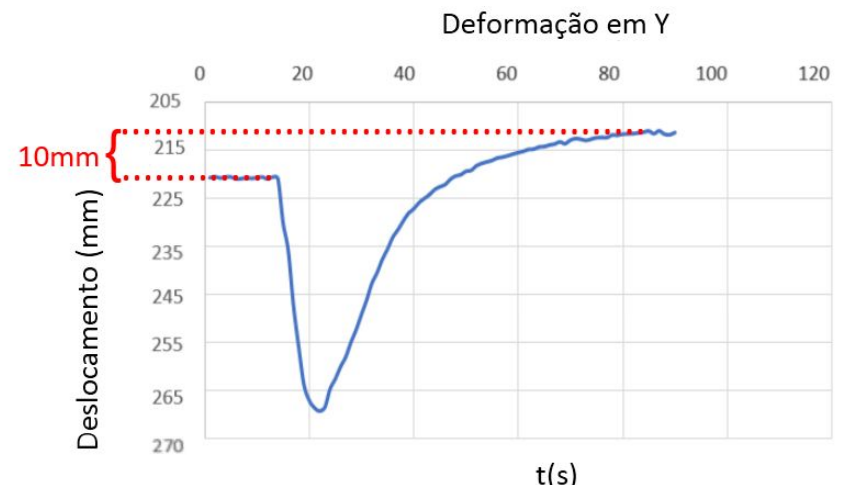

$\mathrm{t}(\mathrm{s})$

Figura 14. Resultados do deslocamento proveniente da Deformação $Y$ ao longo do tempo t, com a nova configuração do sistema.

Ao medir o movimento do ponto verde no painel, identificou-se que os valores apresentavam uma variação máxima de apenas 1 milímetro, em relação ao real, ou seja a relação de conversão pixel por milímetro, o que permite validar o método da medição proposto.

Assim como no teste anterior e representado pela Figura 14, o mesmo ocorre na Figura 13, porém com menor intensidade, sendo que ao iniciar a soldagem ocorre um deslocamento ao longo do eixo $\mathrm{Y}$, proveniente da expansão e contração que atinge um valor máximo, e ao término do processo essa distorção é minimizada até um valor que se mantém estável.

A deposição de camadas sucessivas foi realizada, e o monitoramento da distorção foi realizada através do acompanhamento do deslocamento do feixe laser. Os dados de deslocamento também foram obtidos, armazenados em forma de planilha, e obtido o gráfico conforme apresentado na Figura 15. 


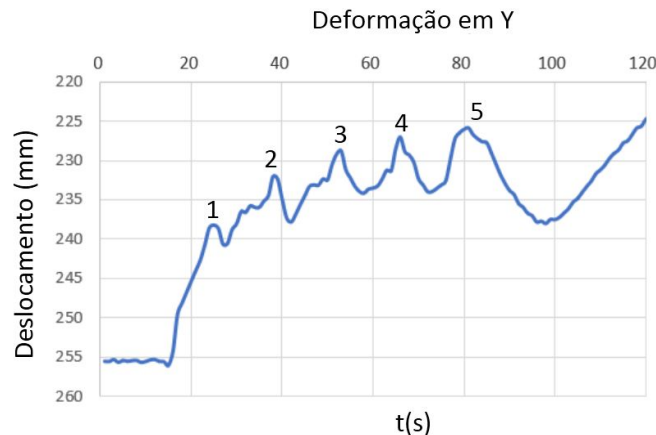

Figura 15. Resultados do deslocamento proveniente da Deformação $Y$ ao longo do tempo t, com deposição de 5 camadas sucessivas.

É possível observar na Figura 15 a evolução da deformação que ocorre no eixo Y com o depósito de cada uma das 5 camadas. Ainda nesta figura é possível verificar que com a adição de camadas o incremento da altura do cordão depositado provoca menores variações de deformações ao longo do eixo Y. Para avaliar a influência do número de camadas em relação a deformação, foram realizados dois testes com o depósito de 5 cordões cada, sendo medido suas alturas ao fim de cada soldagem, e as variações de deformações.

Os resultados obtidos pela captura da informação da variação da posição da projeção do laser estão expressos na Figura 16a e 16b, sendo que para o primeiro teste ao avaliar as distâncias entre o início e o último cordão depositado obtém-se uma deformação máxima de $38 \mathrm{~mm}$ no sentido $Y$.

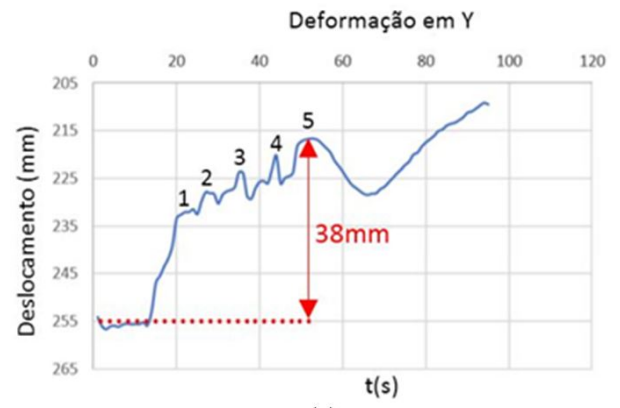

(a)

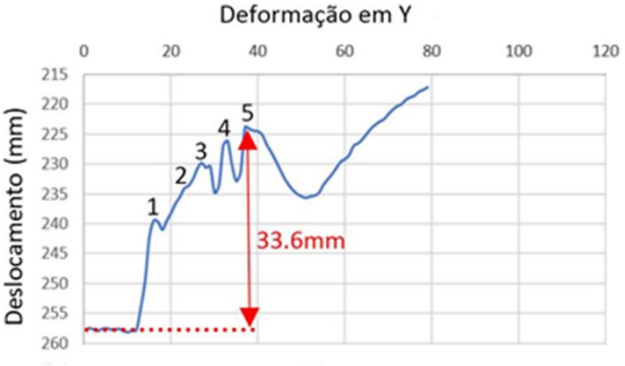

$t(s)$

Figura 16. Resultados das deformações do deslocamento proveniente da Deformação Y ao longo do tempo t. (a) Teste 1; (b) Teste 2.

Para o segundo teste, o deslocamento médio no eixo $Y$ foi de $33.6 \mathrm{~mm}$, o que resulta em uma menor deformação em relação ao primeiro teste, devido a redução do valor do calor conduzido ao longo do perfil produzido.

O que difere o Teste 1 do Teste 2 é o comprimento do cordão depositado, sendo mantidos todos os outros parâmetros de soldagem. No primeiro teste a extensão é de $150 \mathrm{~mm}$ enquanto que no segundo o valor foi de $100 \mathrm{~mm}$.

Os valores dos resultados dos testes 1 e 2 estão representados na Tabela 3, além dos valores das deformações máximas projetadas pelo feixe laser e capturada pelo sistema de visão em cada passe a partir da posição inicial. É possível observar um comportamento da redução das deformações interpasses, que pode estar associado ao gradiente de dissipação de calor que sofre alteração de acordo com o acréscimo de camadas.

Tabela 3. Cordões depositados.

\begin{tabular}{cccc}
\hline Teste & Número do cordão (\#) & Altura do Cordão $(\mathbf{m m})$ & Deformação projetada $(\mathbf{m m})$ \\
& 1 & 2.1 & 17 \\
Teste 1 & 2 & 4.2 & 25 \\
& 3 & 5.7 & 32 \\
& 4 & 6.7 & 35 \\
Teste 2 & 5 & 8.1 & 18.5 \\
& 1 & 2.7 & 19.5 \\
& 2 & 4.6 & 27.5 \\
\end{tabular}


Correlacionando os dados obtidos através do sistema de monitoramento e os valores finais reais da deformação da chapa foi identificado uma variação de $5 \%$. Vale ressaltar que os valores referentes a deformação das chapas foram medidos após o resfriamento total das mesmas.

\section{Conclusões}

Os resultados experimentais confirmaram a possibilidade de monitorar quantitativamente em tempo real a variação do ponto projetado do feixe laser devido as deformações das chapas quando submetidas a ciclos térmicos, utilizando para isso dados coletados através de sensores que projetam o deslocamento em pontos afastados do cordão de solda.

O algoritmo desenvolvido apresentou excelente eficiência quanto a influência de iluminação externa e até mesmo do próprio arco elétrico, suprimindo todos os comprimentos de onda que não estivessem relacionados a luz verde do laser.

A avaliação e quantificação da deformação ao longo do processo de soldagem utilizando equipamentos de baixo valor agregado, se demonstrou eficiente, e pode auxiliar nas tomadas de decisões nos procedimentos de soldagem.

A obtenção de informações de distorções durante o processo de soldagem apresenta-se útil para reduzir os custos de fabricação, de modo a possibilitar realimentar a trajetória de um robô e alterando os parâmetros para um menor aporte térmico nas regiões que apresentaram elevados valores de distorção.

É sabido da necessidade de uso de filtros para minimizar as interferências causadas pela luminosidade do arco elétrico, porém vale ressaltar que estes não foram utilizados neste primeiro trabalho, pois os autores pretendem avaliar a funcionalidade de sua proposta. O que foi possível identificar como melhoria para o trabalho futuro, o uso de lasers vermelhos $(650 \mathrm{~nm})$ e filtros passa banda para reduzir interferências luminosas externas.

\section{Agradecimentos}

Os autores agradecem à Universidade Federal de Minas Gerais, em particular ao LRSS - Laboratório de Robótica Soldagem e Simulação do Departamento de Engenharia Mecânica, por disponibilizarem os recursos necessários para a realização deste e também pela parceria com a Universitê de Rennes 1.

\section{Referências}

[1] Modenesi PJ, Marques PV, Santos DB. Introdução à Metalurgia da soldagem. Belo Horizonte: UFMG; 2012 [acesso em 10 out. 2019 ]. Disponível em: http://https://demet.eng.ufmg.br/wp-content/uploads/2012/10/metalurgia.pdf

[2] Antunes AEB. Tensões residuais na soldagem: aspectos básicos. Journal of the Brazilian Society of Mechanical Sciences. 1995;17(4):394403.

[3] Amante DAM. Imperfeições de fabricação na construção naval e offshore [monografia]. Rio de Janeiro: Escola Politécnica, Universidade Federal do Rio de Janeiro; 2006.

[4] Masubuchi K. Analysis of welded structures: residual stresses, distortion, and their consequences. Vol. 33. Londres: Pergamon Press; 1980.

[5] Araújo DB. Estudo de distorções em soldagem com técnicas numéricas e de otimização [tese de doutorado]. Uberlândia: Escola de Engenharia Mecânica, Universidade federal de Uberlândia; 2012.

[6] Pereira JH, Bracarense AQ. Monitoramento contínuo das distorções ocorridas na soldagem GMAW Robotizado de um modelo em escala reduzida de anel segmentado utilizando sensores a Laser. In: Anais do XLI Congresso Nacional de Soldagem; 2015; Salvador, BA. São Paulo: ABS; 2015.

[7] Rogana WG, Bracarense AQ. Projeto de um simulador dinâmico de carregamento para minimização de distorções e tensões térmicas e residuais geradas em cordões de solda. In: Anais do XV Congresso Brasileiro de Engenharia Mecânica; 1999, Águas de Lindóia, SP. Rio de Janeiro: ABCM; 1999.

[8] Miranda LH, Bracarense AQ. Redução das distorções angulares em cordões de solda sobre chapa de aço de baixo carbono com a utilização da refrigeração forçada da poça de fusão. Tecnologia em Metalurgia e Materiais. 2007;4(2):17-20. http://dx.doi.org/10.4322/tmm.00402004.

[9] Camera Calibration Toolbox for MatLab. 2018 [acesso em 10 dez. 2018]. Disponível em: http:// www.vision.caltech.edu/bouguetj/calib_doc

[10] Wei G-Q, De Ma S. Implicit and explicit camera calibration: theory and experiments. IEEE Transactions on Pattern Analysis and Machine Intelligence. 1994;16(5):469-480. http://dx.doi.org/10.1109/34.291450. 